\section{Dynamic association of capping enzymes with transcribing RNA polymerase II}

\author{
Stephanie C. Schroeder, ${ }^{1}$ Beate Schwer, ${ }^{2}$ \\ Stewart Shuman, ${ }^{3}$ and David Bentley ${ }^{1,4}$ \\ ${ }^{1}$ Department of Biochemistry and Molecular Genetics, \\ UCHSC, Denver, Colorado 80262, USA; ${ }^{2}$ Department \\ of Microbiology and Immunology, Weill Medical College \\ of Cornell University, New York, New York 10021, USA; \\ ${ }^{3}$ Memorial Sloan-Kettering Cancer Center, \\ New York, New York 10021, USA
}

The C-terminal heptad repeat domain (CTD) of RNA polymerase II (pol II) is proposed to target pre-mRNA processing enzymes to nascent pol II transcripts, but this idea has not been directly tested in vivo. In vitro, the yeast mRNA capping enzymes Ceg1 and Abd1 bind specifically to the phosphorylated CTD. Here we show that yeast capping enzymes cross-link in vivo to the 5 ' ends of transcribed genes and that this localization requires the CTD. Both the extent of CTD phosphorylation at Ser 5 of the heptad repeat and the binding of capping enzymes decreased as polymerase moved from the $5^{\prime}$ to the $3^{\prime}$ ends of the ACT1, ENO2, TEF1, GAL1, and GAL10 genes. Ceg1 is released early in elongation, but Abd1 can travel with transcribing pol II as far as the $3^{\prime}$ end of a gene. The CTD kinase, Kin28, is required for binding, and the CTD phosphatase, Fcp1, is required for dissociation of capping enzymes from the elongation complex. CTD phosphorylation and dephosphorylation therefore control the association of capping enzymes with pol II as it transcribes a gene.

Received July 18, 2000; revised version accepted August 24, 2000 .

The conserved CTD of the pol II large subunit has dual functions in controlling transcriptional responses (Scafe et al. 1990; Gerber et al. 1995) and in coordinating premRNA synthesis with processing. It has been suggested that the CTD serves as a landing pad for processing factors and thereby targets them specifically to transcripts made by pol II and not by other RNA polymerases (Yuryev et al. 1996; Du and Warren 1997; McCracken et al. 1997a,b; Hirose and Manley 1998; Bentley 1999; Misteli and Spector 1999; Hirose and Manley 2000). It remains to be shown directly, however, that processing factors actually contact the CTD of transcribing pol II in

[Key Words: CTD; Fcp1; transcription; elongation; Abd1; Ceg1; mRNA cap]

${ }^{4}$ Corresponding author.

E-MAIL david.bentley@UCHSC.edu; FAX (303) 315-8215.

Article and publication are at www.genesdev.org/cgi/doi/10.1101/ $\operatorname{gad} .836300$. vivo. The CTD comprises tandem heptad repeats (consensus YSPTSPS) that are multiply phosphorylated on Ser 2 and Ser 5 by Ctk1, Srb10, and the TFIIH-associated kinase Kin28/cdk7 (Feaver et al. 1994; Liao et al. 1995; Sterner et al. 1995; Dahmus 1996; Hengartner et al. 1998). The CTD is dephosphorylated by the phosphatase Fcp1 (Chambers and Dahmus 1994; Cho et al. 1999; Kobor et al. 1999). Activation of the Drosophila Hsp70 gene involves a switch from hypophosphorylated pol II paused at the $5^{\prime}$ end before heat shock to a mix of phosphorylated and nonphosphorylated forms at 5' and 3' ends after heat shock (O'Brien et al. 1994). It is not known, however, if the state of CTD phosphorylation or the protein composition (Otero et al. 1999) of the elongation complex changes as pol II travels through a gene.

The importance of the phosphorylated CTD for premRNA capping is supported by genetic and biochemical evidence (Cho et al. 1997; McCracken et al. 1997a; Rodriguez et al. 2000). The yeast-capping enzymes Ceg1 (which adds the unmethylated GpppRNA cap) and Abd1 (which methylates the cap to form m7GpppRNA) bind directly to the phosphorylated CTD in vitro (Cho et al. 1997; McCracken et al. 1997a; Yue et al. 1997). An outstanding question is whether the capping enzymes actually associate with pol II elongation complexes in vivo in a manner that requires CTD phosphorylation.

\section{Results and Discussion}

\section{Capping enzymes localize to sites of transcription in vivo}

We used in vivo formaldehyde cross-linking, chromatin immunoprecipitation (ChIP; Strahl-Bolsinger et al. 1997), and PCR analysis of precipitated DNA to ask whether capping enzymes are physically present on transcribed genes in budding yeast. Formaldehyde treatment produces a network of protein-protein and protein-DNA cross-links that, in theory, permits detection of proteins that are directly or indirectly in contact with a particular DNA sequence. In Figure 1A, cross-linked chromatin from isogenic RPB1 and $r p b 1-1$ strains (Nonet et al. 1987) with a HA epitope tag on the Rpb3 subunit of pol II were immunoprecipitated with either monoclonal anti-HA or polyclonal antibodies against the CTD of Rpb1, Abd1, or Ceg1. The anti-CTD antibody reacted equally well with biotinylated (YSPTSPS) ${ }_{4}$ synthetic peptides that were either unphosphorylated or phosphorylated at Ser 2 or Ser 5 of each repeat (Fig. 1C, lanes 2-4). Anti-Abd1 recognizes a single band and anti-Ceg1 recognizes a doublet in Western blots of yeast whole-cell extract (McCracken et al. 1997a; Wang and Shuman 1997; data not shown). ChIP with anti-myc monoclonal antibody in a strain with this epitope tag on Abdl gave similar results to the polyclonal anti-Abdl antibody (data not shown).

The experiment in Figure 1A shows that the capping enzymes Ceg1 and Abd1, as well as the Rpb1 and Rpb3 


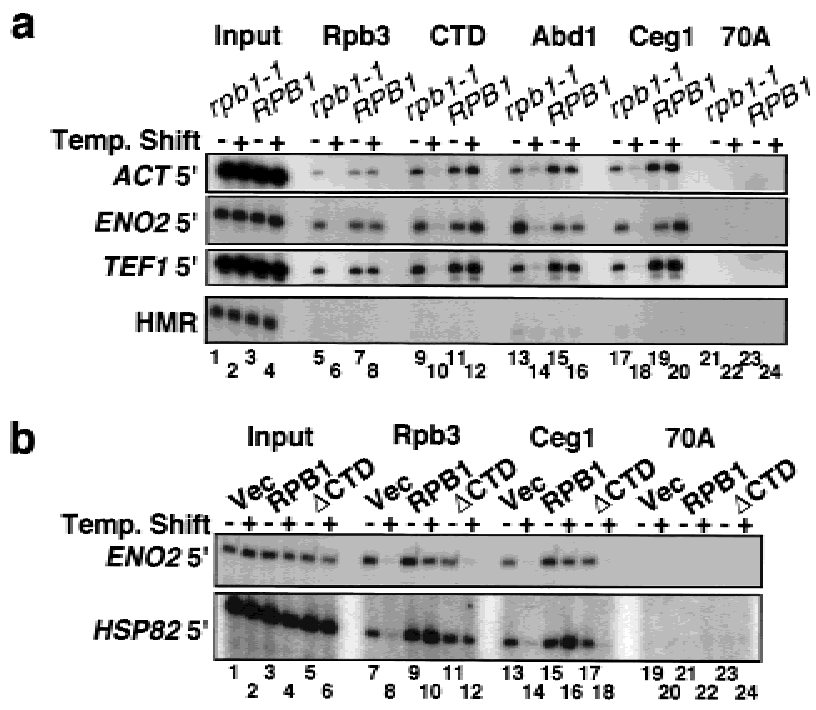

C

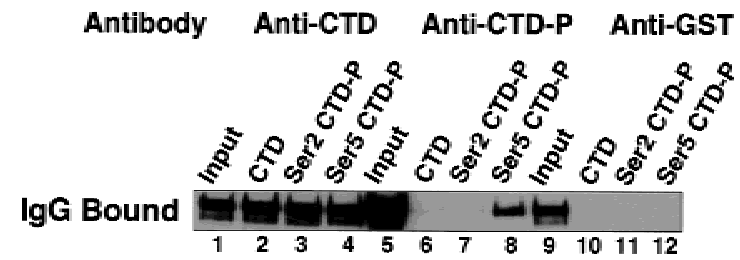

Figure 1. Cross-linking of capping enzymes to transcribed genes in vivo requires functional pol II and the CTD. (A) ChIP analysis of wild-type RPB1 and isogenic rpb1-1 mutants at $25^{\circ} \mathrm{C}$ and $37^{\circ} \mathrm{C}(-$ and +$) .{ }^{32} \mathrm{P}$-labeled PCR products for input and IPs with the indicated antibodies are shown. 70A is an irrelevant control antibody. (B) ChIP analysis of the rpb1-1 strain DBY154 containing vector plasmid pFL38, pFL38-RPB1, or pFL38rpb1 $\triangle \mathrm{CTD}\left(\mathrm{McNeil}\right.$ et al. 1998 ) at $25^{\circ} \mathrm{C}$ and $37^{\circ} \mathrm{C}$. (C) Specificity of the anti-CTD antibodies. Rabbit anti-CTD, anti-CTD-P, and anti-GST control antibody was bound to synthetic peptides (see Materials and Methods) immobilized on magnetic beads. Bound IgG was immunoblotted with antirabbit IgG. The heavy chain band is shown.

subunits of pol II, cross-link in vivo to the $5^{\prime}$ ends of the constitutively transcribed ACT1, ENO2, and TEF1 genes. In contrast, little or no cross-linking occurred at the silent mating type locus, $H M R$ (Fig. 1A, lanes $7,11,15,19$ ), the nontranscribed telomere VI R, or the mitochondrial gene COX3 (data not shown).

When transcription was inhibited by shifting the rpb1-1 ts mutant to $37^{\circ} \mathrm{C}$ for $45 \mathrm{~min}$, the cross-linking of capping enzymes and pol II were significantly diminished (Fig. 1A, lanes 6,10,14,18), whereas heat shock of the isogenic RPB1 strain had little effect (Fig. 1A, lanes $8,12,16,20)$. The HA-Rpb3 protein is stable in rpb1-1 cells at $37^{\circ} \mathrm{C}$ for $>60 \mathrm{~min}$ (data not shown), yet it does not cross-link to DNA at this temperature, providing strong support for the specificity of the in vivo cross-linking reaction. In summary, the experiment in Figure $1 \mathrm{~A}$ shows that capping enzymes bind in vivo to the 5 ' ends of transcribed genes and that this localization requires ongoing transcription.

\section{CTD-dependent recruitment of Ceg1 to sites of transcription}

The CTD requirement for recruitment of the capping enzyme Ceg1 was tested at the HSP82 gene, which can be transcribed by the CTD-deleted form of pol II (McNeil et al. 1998). Pol II and Ceg1 cross-linking to HSP82 was severely reduced when a $r p b 1-1$ ts mutant carrying a control vector plasmid was shifted to $37^{\circ} \mathrm{C}$ (Fig. 1B, cf. lanes $7,13$ with 8,14$)$. When the wild-type $R P B 1$ gene was provided on a plasmid, then heat shock increased the extent of Ceg1 and Rpb3 cross-linking to HSP82 (Fig. 1B, cf. lanes 9,15 with 10,16$)$. In the $r p b 1-1$ strain carrying the $r p b 1-\triangle C T D$ gene on a plasmid, the only active pol II at $37^{\circ} \mathrm{C}$ is the form that lacks the CTD. $\Delta$ CTD-pol II, detected with antibody, against HA-Rpb3 was cross-linked to $H S P 82$ at $37^{\circ} \mathrm{C}$, but very little Ceg1 cross-linking was detected (Fig. 1B, lanes 12,18). In the same cells at $25^{\circ} \mathrm{C}$, however, when the rpb1-1 polymerase containing a fulllength CTD was engaged (Fig. 1B, lane 11), then significant Ceg1 cross-linking to HSP82 was observed (Fig. 1B, lane 17). Ceg1 cross-linking to HSP82, as quantified by phosphorimager analysis of the ChIP signal normalized to input, showed an $80 \%$ reduction when the $\Delta r p b 1$ $\triangle C T D$ strain was shifted to $37^{\circ} \mathrm{C}$ (Fig. 1B lanes 17,18 ), whereas Rpb3 cross-linking declined by only $2 \%$ (Fig. 1B, lanes 11,12). We conclude from the experiment in Figure $1 \mathrm{~B}$ that the CTD is necessary for the association of Ceg1 with a transcribed gene.

\section{Kin28-dependent recruitment of capping enzymes}

The importance of CTD phosphorylation for recruitment of capping enzymes was tested in a ts mutant of Kin28 that phosphorylates Ser 5 of the heptad repeat (Hengartner et al. 1998). After inactivation of this kinase at $37^{\circ} \mathrm{C}$, a reduced but significant amount of pol II remained at ACT1 and ENO2, as detected by the anti-CTD and anti-HA-Rpb3 immunoprecipitation (Fig. 2A, lanes 8,12). CTD phosphorylation was monitored by ChIP with a polyclonal antibody that reacts with heptads phosphorylated on Ser 5 but not with nonphosphorylated heptads or those phosphorylated at Ser 2 (see Fig. 1C, lanes 6-8). The pol II remaining at ACT1 and ENO2 after inactivation of Kin28 had reduced reactivity with the Ser 5- $\mathrm{PO}_{4}$-specific antibody (Fig. 2A, lane 16) consistent with loss of kinase activity. Significantly, this hypophosphorylated pol II was not associated with Abd1 or Ceg1 (Fig. 2A, lanes 20,24). We conclude that Kin28 is required for normal levels of pol II binding, CTD phosphorylation at Ser 5, and recruitment of the capping enzymes. In contrast, inactivation of the nonessential CTD kinases by deletion of CTK1 (Sterner et al. 1995) or point mutation of SRB10 (D260A; Liao et al. 1995) did not significantly reduce either CTD phosphorylation at Ser 5 or recruitment of capping enzymes to ACT1 or ENO2 as judged by ChIP assays (data not shown).

\section{CTD dephosphorylation during elongation}

Is the CTD phosphorylation and binding of capping enzymes that is established at the $5^{\prime}$ end of the gene main- 


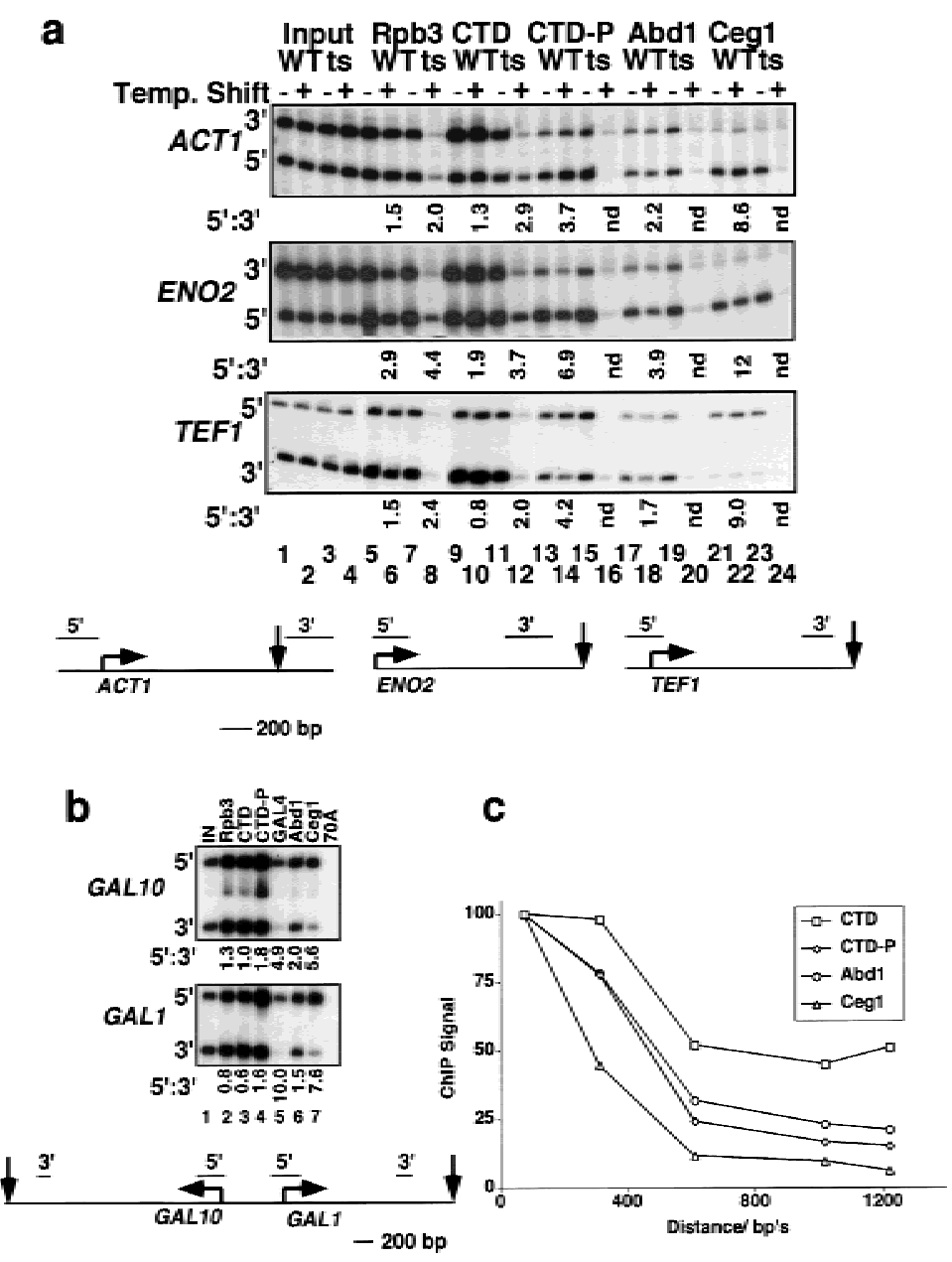

Figure 2. 5' $-3^{\prime}$ distribution of pol II, and capping enzymes and the effect of Kin28 inactivation. (A) ChIP analysis of kin28-ts3 and isogenic wild type strains (Valay et al. 1993) at $25^{\circ} \mathrm{C}$ and $37^{\circ} \mathrm{C}$. Ratios of $5^{\prime}: 3^{\prime} \mathrm{ChIP}$ signals that are normalized to input are given below selected lanes. The normalization controls for any differences in PCR amplification efficiency between $5^{\prime}$ and 3' gene segments. The AUG and Ter codons and 5' and 3' PCR products are diagrammed. (B) Distribution of pol II and capping enzymes along GAL1 and GAL10 genes. ChIP analysis 30 min after addition of $2 \%$ galactose to a culture grown in $\mathrm{YP}+2 \%$ raffinose. Normalized ratios of $5^{\prime}: 3^{\prime} \mathrm{ChIP}$ signals are shown below the lanes. The positions of $5^{\prime}$ and $3^{\prime}$ PCR products are diagrammed. $(C)$ Distribution of total pol II (CTD), Ser 5 phosphorylated pol II (CTD-P), Abd1, and Ceg1 along the ENO2 gene. Results are average ChIP signals relative to input for four experiments. Standard errors were $<10 \%$. The four wild-type strains used were the same as those in Fig. 1B: DBY154 (pFL38-RPB1); Fig. 2A: GF262 (Valay et al. 1993); Fig. 3: YBS2(pGYCE358CEG1) (Schwer et al. 1998); and the YMK16 FCP1 strain isogenic to the fcp1-1 mutant (Kobor et al. 1999). The 5'-most PCR product was set to $100 \%$ for each antibody. PCR primers were generated to cover $\sim 200$-bp regions spaced throughout the ENO2 gene. Distances are from the ATG to the middle of each PCR product. The ENO2 primer pairs used in A correspond to the points at 100 and $1050 \mathrm{bp}$ from the ATG.

tained as pol II travels to the $3^{\prime}$ end? To address this question, we compared the cross-linking of pol II and capping enzymes to the $5^{\prime}$ and $3^{\prime}$ ends of the constitutively expressed ENO2, ACT1, and TEF1 genes and the inducible GAL1 and GAL10 genes (Fig. 2). Total pol II cross-linking was determined by ChIP with antiHA-Rpb3 and anti-CTD antibodies, and phosphorylated pol II was monitored with antibody specific to the Ser 5 phosphorylated CTD. Remarkably, the polymerases near the $5^{\prime}$ end were more highly phosphorylated than polymerases near the $3^{\prime}$ end; that is, the $5^{\prime}: 3^{\prime}$ ratios for phosphorylated pol II were always greater than those for total pol II (Fig. 2A, cf. lanes 13-15 with 5-7 and 9-11; Fig. 2B, lanes 2-4). Because the antiphospho-CTD antibody efficiently recognizes partially phosphorylated CTD (data not shown), the ChIP assay probably underestimates the extent of dephosphorylation during elongation. We conclude that there is a net dephosphorylation of pol II at Ser 5, as it traverses the ACT1, ENO2, TEF1, GAL1, and GAL10 genes. Although pol II is dephosphorylated during elongation, phosphorylation by Kin28 still appears to be important for promoter clearance and/or early elongation (Akoulitchev et al. 1995; Akhtar et al. 1996), as the pol II remaining after Kin28 inactivation was mostly confined to the $5^{\prime}$ ends of $A C T 1$ and ENO2 (Fig. 2A, cf. lanes 8,12 with 6,10).

\section{Ceg1 is released early but Abd1 travels with pol II elongation complexes}

Ceg1 and Abd1 bind only to the phosphorylated CTD in vitro (McCracken et al. 1997a). Therefore, we reasoned that dephosphorylation during elongation might be linked to release of capping enzymes. This prediction was supported by ChIP, which showed that cross-linking of capping enzymes to $3^{\prime}$ ends was less than cross-linking to $5^{\prime}$ ends on all five genes we examined (Fig. 2A, lanes 17-19, 21-23; Fig. 2B, lanes 6,7). Unexpectedly, Ceg1 and Abd1 were not distributed in the same way along these genes however; the $5^{\prime}-3^{\prime}$ gradients of Ceg1 cross-linking were significantly steeper than those for Abd1. This point is illustrated in the KIN28 wild-type strain at $37^{\circ} \mathrm{C}$, where the $5^{\prime}: 3^{\prime}$ ratios for Abd1 were 2.2, 3.9, and 1.7 on the ACT1, ENO2, and TEF1 genes, respectively, compared to 8.6, 12, and 9.0 for Ceg1 (Fig. 2A, lanes 18,22$)$. Similarly, the ChIP $5^{\prime}: 3^{\prime}$ ratios for Abd1 on the induced GAL1 and GAL10 genes were only 1.5 and 2.0 , respectively, compared to ratios of 7.6 and 5.6 for Ceg1 on the same genes (Fig. 2B, lanes 6,7). In fact, the $5^{\prime}: 3^{\prime}$ ratios for Ceg 1 on the GAL genes were similar to those for the Gal4 transcription factor (Fig. 2B, cf. lanes 5 and 7). Assuming that Gal4 is localized exclusively at the promoters, this result confirmed that Ceg1 was mostly restricted to the 5' ends of GAL1 and GAL10, whereas Abd1 was more evenly distributed between the $5^{\prime}$ and $3^{\prime}$ ends.

Changes in the composition of the pol II elongation complex as it traversed the $1.3-\mathrm{kb}$ ENO2 gene were mapped in more detail using five primer pairs spaced 
throughout the ORF. The average values for four experiments in four different strains are plotted in Figure 2C. Of the total pol II recruited to the $5^{\prime}$ end of ENO2, 50\% remained at the $3^{\prime}$ end as determined by either anti-CTD (Fig. 2C) or anti-HA-Rpb3 ChIP (Fig. 2A, lane 6; data not shown). This observation suggests that some premature termination of transcription occurs on the ENO2 gene. In contrast to total pol II, only $15 \%$ of the initial $5^{\prime}$ level of Ser 5 phosphorylated pol II remained at the $3^{\prime}$ end (Fig. $2 \mathrm{C})$, with most of the loss in phosphorylation occurring within $\sim 600$ bases of the start site. Of the initial $5^{\prime}$ amount of cross-linked Abd1, 21\% remained at the $3^{\prime}$ end, compared to only $6 \%$ of Ceg1. Ceg1 cross-linking fell precipitously within the first 600 bases of the transcription unit. These data demonstrate that Ceg1 is released from pol II early, while Abdl is released later in elongation. Furthermore, the results indicate that a significant fraction of the elongating pol II carries Abd1 to the $3^{\prime}$ end of the ENO2 gene.

\section{Abd1 is recruited to sites of pol II transcription independent of Ceg1}

Although Abd1 cross-linking is resistant to the RNase treatment in the ChIP protocol (see Materials and Methods), it is possible that Abd1 remains associated with elongation complexes by a mechanism that requires recognition of its substrate: the 5' cap guanylate added by Ceg1. We tested this possibility using two ceg1 ts mutants that are defective for capping at restrictive temperature (Schwer et al. 1998). Cegl cross-linking to the ACT1, HSP82, and ENO2 genes was abolished in both ts strains at $37^{\circ} \mathrm{C}$ (Fig. 3, lanes 16,18 ), but not in the wild type (Fig. 3, lane 14). In contrast to the complete loss of Ceg1 cross-linking in the ts strains at $37^{\circ} \mathrm{C}$, significant amounts of $\mathrm{Abd} 1$ remained associated with transcription complexes on all three genes examined (Fig. 3, lanes 10,12). For reasons we do not understand, Ceg1-13 had no significant effect on Abd1 recruitment at the nonpermissive temperature (Fig. 3, lane 12), whereas ceg1-3 partially reduced Abd1 recruitment (Fig. 3, lane 10). The ratio of Abd1 at the $5^{\prime}$ and $3^{\prime}$ ends of the ENO2 gene was unaffected by either $\operatorname{ceg} 1$ ts allele, indicating that Abd1's ability to travel with pol II is independent of Ceg1 (data not shown). Ceg1 inactivation also had no effect on pol II recruitment or CTD phosphorylation on Ser 5 (data not

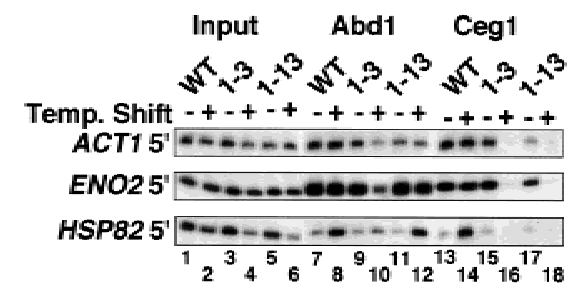

Figure 3. Abd1 binds pol II elongation complexes independently of Ceg1. ChIP analysis of isogenic wild-type, ceg1-3 and ceg1-13 cells (Schwer et al. 1998) at $25^{\circ} \mathrm{C}$ and $37^{\circ} \mathrm{C}$. CTD and phospho-CTD cross-linking were unaffected by the ceg1 mutants (data not shown). a

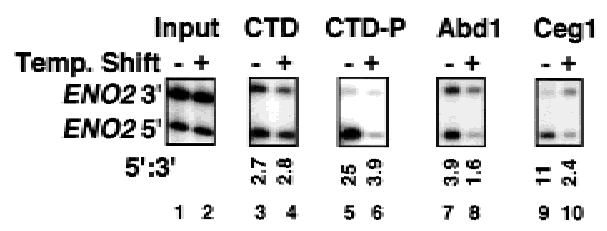

b

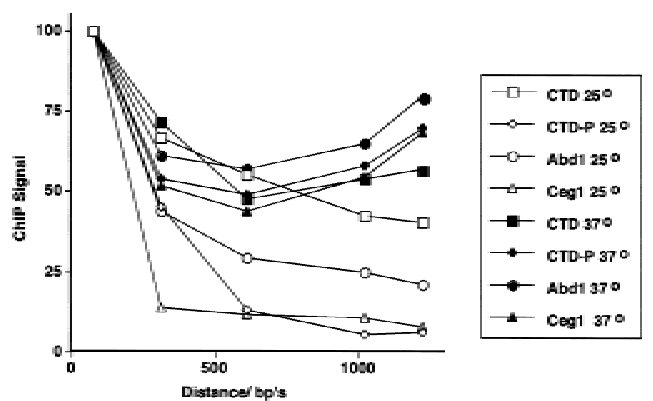

Figure 4. Inactivation of Fcpl prevents CTD dephosphorylation and release of capping enzymes from pol II elongation complexes. (A) ChIP analysis of $f c p 1-1$ ts mutant (Kobor et al. 1999) at $25^{\circ} \mathrm{C}$ and $37^{\circ} \mathrm{C}$. The ENO2 $5^{\prime}$ and $3^{\prime}$ PCR products are located 100 and $1050 \mathrm{bp}$ from the ATG (see Fig. 2A). Under each lane is the ratio of $5^{\prime}: 3^{\prime}$ ChIP signals after normalization to input. These ratios were not significantly affected when the isogenic wild-type strain was shifted to $37^{\circ} \mathrm{C}$ (data not shown). This result is representative of three independent ChIP experiments. (B) Distribution of total pol II (CTD), Ser 5 phosphorylated pol II (CTD-P), Abd1, and Ceg1 along the ENO2 gene in the fcp1-1 mutant at $25^{\circ} \mathrm{C}$ and $37^{\circ} \mathrm{C}$. ChIP signals normalized to input were plotted as in Figure 2C. Note that the data are adjusted to $100 \%$ at the $5^{\prime}$ end and do not reflect the reduced level of Ser 5 phosphorylation at $37^{\circ} \mathrm{C}$ relative to $25^{\circ} \mathrm{C}$ (Fig. $4 \mathrm{~A}$, lanes 5,6 ).

shown) at the ACT1, ENO2, and HSP82 genes. We conclude that protein-protein interaction rather than Abd1substrate interaction is responsible for localizing Abd1 to pol II elongation complexes.

\section{Fcp1-dependent release of capping enzymes from elongation complexes}

The experiment in Figure 2C suggests that dephosphorylation of the CTD could actually be the signal that releases capping enzymes from pol II elongation complexes. This hypothesis was tested using a ts mutant of the Fcp1 CTD phosphatase. We reasoned that if Fcp1 dephosphorylates elongation complexes and if dephosphorylation signals release of capping enzymes, then inactivation of Fcpl should reduce the $5^{\prime}: 3^{\prime}$ gradient of capping enzymes. Fcp1 is required for re-cycling of pol II and for expression of most genes in yeast (Cho et al. 1999; Kobor et al. 1999). At the permissive temperature of $25^{\circ} \mathrm{C}$, the $f_{c p} 1-1$ ts mutant (Kobor et al. 1999) grows slowly and has reduced pol II recruitment to ENO2, as expected for a partial recycling defect (data not shown). ChIP analysis at $25^{\circ} \mathrm{C}$ and $37^{\circ} \mathrm{C}$ shows that Fcp 1 inactivation had no effect on the $5^{\prime}: 3^{\prime}$ distribution of total pol II (Fig. 4A, lanes 3,4$)$ but greatly reduced the $5^{\prime}: 3^{\prime}$ gradient of Ser 5 phosphorylated pol II (lanes 5,6$)$. Note that the 
$5^{\prime}: 3^{\prime}$ ratio for Ser 5 phosphorylated pol II was only 1.4-fold higher than for total pol II (3.9 vs. 2.8; Fig. 4A, lanes 4,6) after Fcp1 was inactivated. These results show that Fcp1 inactivation reduced dephosphorylation during elongation, as expected. Fcpl inactivation also reduced the cross-linking of phosphorylated CTD at the $5^{\prime}$ end, suggesting an initiation defect. Most important, Fcpl inactivation significantly reduced the $5^{\prime}: 3^{\prime}$ ratios of $\mathrm{Abd} 1$ and Ceg1 cross-linking on ENO2 (Fig. 4A, cf. lanes 7,8 and 9,10).

To examine the effect of Fcp1 inactivation on elongation complexes along the ENO2 gene in more detail, we analyzed immunoprecipitates with the panel of five primer pairs used in Figure 2C. In the $f_{c p} 1-1$ strain at $25^{\circ} \mathrm{C}$, total pol II, phosphorylated pol II, Ceg1, and Abd1 were distributed in a similar way to wild-type strains (Fig. 2C; Fig. 4B, open symbols). When Fcp1 was inactivated at $37^{\circ} \mathrm{C}$, however, cross-linking of phosphorylated pol II, Abd1, and Ceg1 were all significantly increased at the $3^{\prime}$ end relative to the $5^{\prime}$ end (Fig. 4B, filled symbols). In the isogenic FCP1 wild-type strain, a shift to $37^{\circ} \mathrm{C}$ had no effect on the distribution of total pol II, phosphorylated pol II, or capping enzymes (data not shown; see also Fig. 2A, WT strain). This experiment shows that reduced CTD dephosphorylation during elongation in the $f c p 1-1$ mutant at $37^{\circ} \mathrm{C}$ prevented the dissociation of capping enzymes and, therefore, implies that CTD dephosphorylation is at least part of the signal for release of capping enzymes.

This report provides evidence that mRNA capping enzymes bind to pol II in vivo via independent interactions of Ceg1 and Abd1 with the phosphorylated CTD as RNA is being synthesized. The association of capping enzymes with pol II is dynamic; they bind at the $5^{\prime}$ end and are released further downstream. This cycle of binding and release is regulated by Kin28-dependent phosphorylation of the CTD heptad repeats on Ser 5 at the 5' end of the gene and by Fcp1-dependent dephosphorylation of these residues within the transcription unit. Ceg1 is normally released early, while Abd1 is released later. Some Abd1 accompanies pol II at the $3^{\prime}$ end of the gene, suggesting that these two enzymes travel long distances together. The persistent binding of Abd1 to the elongation complex does not require interaction with the RNA cap (Fig. 3). Why Abd1 should remain in contact with pol II at the $3^{\prime}$ end of a gene is unknown, and our findings raise the possibility that sites of Abd1 action are not limited to the $5^{\prime}$ end of the gene. Interestingly, the vaccinia virus-capping enzyme travels with the elongation complex of vaccinia RNA polymerase and serves an essential role in viral mRNA $3^{\prime}$-end formation as a transcription termination factor (Hagler et al. 1994).

\section{Materials and methods}

Yeast strains and media

Yeast strains were generous gifts of R. Young, J. Greenblatt, M. Kobor, A. Greenleaf, and G. Faye. DBY154 (MATolys2-1288 ura3-52 leu2-3,112 HIS4-912 RPB3-1HA::LEU2 rpb1-1 trp1::HisG I was made by crossing rpb1-1 into the HA-tagged Rpb3 strain Z277 (Kolodziej et al. 1990).Yeast were grown to $A_{600}$ of 1.0 in YEPD or SC-uracil medium. Before formaldehyde cross linking and chromatin immunoprecipitation, ts strains were shifted from $25^{\circ} \mathrm{C}$ to $37^{\circ} \mathrm{C}$ for $45 \mathrm{~min}$.
Antibodies

Monoclonal 70A (Kenny et al. 1990) against mammalian RPA was used as a negative control. Monoclonal 12CA5 detected HA-tagged Rpb3. Rabbit anti-Ceg1 (Schwer and Shuman 1996) and anti-Abd1 (Wang and Shuman 1997) have been described. Rabbit anti-Gal4 was raised against residues 1-147 and affinity purified. Rabbit anti-CTD was raised against GST-mouse CTD (1-52) and affinity purified. On Western blots, this antibody reacted with equal affinity to both phosphorylated and nonphosphorylated forms of yeast RNA pol II (data not shown). Rabbit polyclonal anti-CTD-P was raised against GST-mouse CTD (1-52) phosphorylated on glutathione sepharose beads in Hela extract followed by extensive washing in $1 \mathrm{M} \mathrm{NaCl}$ buffer as described (McCracken et al. 1997a). It was depleted of reactivity to unphosphorylated CTD. Specificity of anti-CTD and anti-CTD-P for different phospho forms of CTD was determined by binding in FA lysis buffer (Strahl-Bolsinger et al. 1997) plus phosphatase inhibitors to biotinylated peptides (YSPTSPS) ${ }_{4}$ (1 nmole) immobilized on streptavidin magnetic beads. Peptides were either nonphosphorylated or phosphorylated on Ser 2 or Ser 5 (Ho and Shuman 1999). After extensive washing in FA-lysis buffer, bound IgG was eluted with SDS sample buffer and analyzed by immunoblotting with antirabbit IgG HRP as shown in Figure 1C.

Formaldehyde cross-linking and chromatin immunoprecipitation Chromatin was prepared as described (Strahl-Bolsinger et al. 1997) with minor modifications. After lysis of the cross-linked cells, the crude extract was sonicated to average size of $500 \mathrm{bp}$, clarified, and adjusted to $0.1 \%$ SDS and $1.0 \%$ sarkosyl in FA-lysis buffer. SDS and sarkosyl were added as above to FA-lysis buffer and FA-lysis buffer/500 mM NaCl washes. After the TE wash, immunoprecipitates were digested with 10 $\mu \mathrm{g}$ of RNAse A for $30 \mathrm{~min}$ at $37^{\circ} \mathrm{C}$. Cross-linked protein/DNA complexes were eluted from protein $\mathrm{A}$ beads at room temperature in a buffer containing $1 \% \mathrm{SDS}$ and $0.1 \mathrm{M} \mathrm{NaHCO}_{3}$. Cross-links were reversed by incubation at $65^{\circ} \mathrm{C}$ over night.

Quantitative PCR

PCR reactions performed under conditions that gave linear template: signal $\left(94^{\circ} \mathrm{C}\right.$ for $40 \mathrm{sec}, 53^{\circ} \mathrm{C}$ for $40 \mathrm{sec}, 72^{\circ} \mathrm{C}$ for $1 \mathrm{~min} ; 20$ cycles; reaction volume $20 \mu \mathrm{L}$ ) were carried out with $1 \%$ of the immune precipitate and $0.01 \%$ of total input DNA. ${ }^{32} \mathrm{P}$-dCTP $(0.1 \mu \mathrm{Ci})$ was added for the last PCR cycle. The PCR products (150-290 bp) were analyzed by electrophoresis through a $6 \%$ polyacrylamide gel containing $7 \mathrm{M}$ urea in TBE buffer. The radiolabeled products were quantified by Phosphorimager, and the signal intensities of the ChIP PCR reaction products were normalized to those of the DNAs amplified from the total input DNA template. The 70A irrelevant antibody and the HMR negative control PCR primers were used in all experiments but are only shown in selected figures.

\section{Acknowledgments}

We thank N. Fong, R. Young, G. Faye, A. Greenleaf, M. Kobor, and J. Greenblatt for strains and antibodies and D. Zorio, T. Blumenthal, and J. Jaehning for comments on the manuscript. This work was funded by NIH grants GM58613 (D.B.) and GM52470 (S.S. and B.S.).

The publication costs of this article were defrayed in part by payment of page charges. This article must therefore be hereby marked "advertisement" in accordance with 18 USC section 1734 solely to indicate this fact.

\section{References}

Akhtar, A., Faye, G., and Bentley, D. 1996. Distinct activated and nonactivated RNA polymerase II complexes in yeast. EMBO J. 15: 46544664 .

Akoulitchev, S., Makela, T.P., Weinberg, R.A., and Reinberg, D. 1995. Requirement for TFIIH kinase activity in transcription by RNA polymerase II. Nature 377: 557-560.

Bentley, D. 1999. Coupling RNA polymerase II transcription with premRNA processing. Curr. Opin. Cell Biol. 11: 347-351.

Chambers, R.S. and Dahmus, M.E. 1994. Purification and characterization of a phosphatase from HeLa cells which dephosphorylates the C-terminal domain of RNA polymerase II. J. Biol. Chem. 269: 2624326248. 
Cho, E.J., Takagi, T., Moore, C.R., and Buratowski, S. 1997. mRNA capping enzyme is recruited to the transcription complex by phosphorylation of the RNA polymerase II carboxy-terminal domain. Genes \& Dev. 11: 3319-3326.

Cho, H., Kim, T.K., Mancebo, H., Lane, W.S., Flores, O., and Reinberg, D. 1999. A protein phosphatase functions to recycle RNA polymerase II. Genes \& Dev. 13: 1540-1552.

Dahmus, M.E. 1996. Reversible phosphorylation of the C-terminal domain of RNA polymerase II. J. Biol. Chem. 271: 19009-19012.

Du, L. and Warren, S.L. 1997. Functional interaction between the carboxy-terminal domain of RNA-polymerase-II and pre-messengerRNA splicing. J. Cell Biol. 136: 5-18.

Feaver, W.J., Svejstrup, J.Q., Henry, N.L., and Kornberg, R.D. 1994. Relationship of cdk-activating kinase and RNA polymerase II CTD kinase TFIIH/TFIIK. Cell 79: 1103-1109.

Gerber, H.P., Hagmann, M., Seipel, K., Georgiev, O., West, M.A., Litingtung, Y., Schaffner, W., and Corden, J.L. 1995. RNA polymerase II $\mathrm{C}$-terminal domain required for enhancer-driven transcription. $\mathrm{Na}$ ture 374: 660-662.

Hagler, J., Luo, Y., and Shuman, S. 1994. Factor-dependent transcription termination by vaccinia RNA polymerase: Kinetic coupling and requirement for ATP hydrolysis. J. Biol. Chem. 269: 10050-10060.

Hengartner, C.J., Myer, V.E., Liao, S.M., Wilson, C.J., Koh, S.S., and Young, R.A. 1998. Temporal regulation of RNA polymerase II by Srb10 and Kin28 cyclin-dependent kinases. Mol. Cell 2: 43-53.

Hirose, Y. and Manley, J.L. 1998. RNA polymerase II is an essential mRNA polyadenylation factor. Nature 395: 93-96.

. 2000. RNA polymerase II and the integration of nuclear events. Genes \& Dev. 14: 1415-1429.

Ho, C. and Shuman, S. 1999. Distinct effector roles for Ser2 and Ser5 phosphorylation of the RNA polymerase II CTD in the recruitment and allosteric activation of mammalian capping enzyme. Mol. Cell 3: 405-411.

Kenny, M.K., Schlegel, U., Furneaux, H., and Hurwitz, J. 1990. The role of human single-stranded DNA binding protein and its individual subunits in simian virus 40 DNA replication. J. Biol. Chem. 265: 7693-7700.

Kobor, M.S., Archambault, J., Lester, W., Holstege, F.C., Gileadi, O., Jansma, D.B., Jennings, E.G., Kouyoumdjian, F., Davidson, A.R., Young, R.A., et al. 1999. An unusual eukaryotic protein phosphatase required for transcription by RNA polymerase II and CTD dephosphorylation in S. cerevisiae. Mol. Cell 4: 55-62.

Kolodziej, P.A., Woychik, N., Liao, S.M., and Young, R.A. 1990. RNA polymerase II subunit composition, stoichiometry, and phosphorylation. Mol. Cell Biol. 10: 1915-1920.

Liao, S.M., Zhang, J., Jeffery, D.A., Koleske, A.J., Thompson, C.M., Chao, D.M., Viljoen, M., van Vuuren, H.J., and Young, R.A. 1995. A kinasecyclin pair in the RNA polymerase II holoenzyme. Nature 374: 193196.

McCracken, S., Fong, N., Rosonina, E., Yankulov, K., Brothers, G., Siderovski, D., Hessel, A., Foster, S., Amgen EST Program, Shuman, S., et al. 1997a. 5'-capping enzymes are targeted to pre-mRNA by binding to the phosphorylated carboxy-terminal domain of RNA polymerase II. Genes \& Dev. 11: 3306-3318.

McCracken, S., Fong, N., Yankulov, K., Ballantyne, S., Pan, G.H., Greenblatt, J., Patterson, S.D., Wickens, M., and Bentley, D.L. 1997b. The C-terminal domain of RNA polymerase II couples messenger RNA processing to transcription. Nature 385: 357-361.

McNeil, J.B., Agah, H., and Bentley, D. 1998. Activated transcription independent of the RNA polymerase II holoenzyme in budding yeast. Genes \& Dev. 12: 2510-2521.

Misteli, T. and Spector, D.L. 1999. RNA polymerase II targets pre-mRNA splicing factors to transcription sites in vivo. Mol. Cell 3: 697-705.

Nonet, M., Scafe, C., Sexton, J., and Young, R. 1987. Eukaryotic RNA polymerase conditional mutant that rapidly ceases mRNA synthesis. Mol. Cell Biol. 7: 1602-1611.

O’Brien, T., Hardin, S., Greenleaf, A., and Lis, J.T. 1994. Phosphorylation of RNA polymerase II C-terminal domain and transcriptional elongation. Nature 370: 75-77.

Otero, G., Fellows, J., Li, Y., de Bizemont, T., Dirac, A.M., Gustafsson, C.M., Erdjument-Bromage, H., Tempst, P., and Svejstrup, J.Q. 1999 Elongator, a multisubunit component of a novel RNA polymerase II holoenzyme for transcriptional elongation. Mol. Cell 3: 109-118.
Rodriguez, C.R., Cho, E.J., Keogh, M.C., Moore, C.L., Greenleaf, A.L., and Buratowski, S. 2000. Kin28, the TFIIH-associated carboxy-terminal domain kinase, facilitates the recruitment of mRNA processing machinery to RNA polymerase II. Mol. Cell Biol. 20: 104-112.

Scafe, C., Chao, D., Lopes, J., Hirsch, J.P., Henry, S., and Young, R.A. 1990. RNA polymerase II C-terminal repeat influences response to transcriptional enhancer signals. Nature 347: 491-494.

Schwer, B. and Shuman, S. 1996. Conditional inactivation of mRNA capping enzyme affects yeast pre-mRNA splicing in vivo. RNA 2: $574-583$.

Schwer, B., Mao, X., and Shuman, S. 1998. Accelerated mRNA decay in conditional mutants of yeast mRNA capping enzyme. Nucleic Acids Res. 26: 2050-2057.

Sterner, D.E., Lee, J.M., Hardin, S.E., and Greenleaf, A.L. 1995. The yeast carboxyl-terminal repeat domain kinase CTDK-I is a divergent cyclin-cyclin-dependent kinase complex. Mol. Cell Biol. 15: 5716-5724.

Strahl-Bolsinger, S., Hecht, A., Luo, K., and Grunstein, M. 1997. SIR2 and SIR4 interactions differ in core and extended telomeric heterochromatin in yeast. Genes \& Dev. 11: 83-93.

Valay, J.G., Simon, M., and Faye, G. 1993. The kin28 protein kinase is associated with a cyclin in Saccharomyces cerevisiae. I. Mol. Biol. 234: 307-310.

Wang, S.P. and Shuman, S. 1997. Structure-function analysis of the mRNA cap methyltransferase of Saccharomyces cerevisiae. J. Biol. Chem. 272: 14683-14689.

Yue, Z., Maldonado, E., Pilluta, R., Cho, H., Reinberg, D., and Shatkin, A. 1997. Mammalian capping enzyme complements mutant Saccharomyces cerevisiae lacking mRNA guanylyltransferase and selectively binds the elongating form of RNA pol II. Proc. Natl. Acad. Sci. 94: 12898-12903.

Yuryev, A., Patturajan, M., Litingtung, Y., Joshi, R., Gentile, C., Gebara, M., and Corden, J. 1996. The CTD of RNA polymerase II interacts with a novel set of SR-like proteins. Proc. Nat1. Acad. Sci. 93: 69756980. 


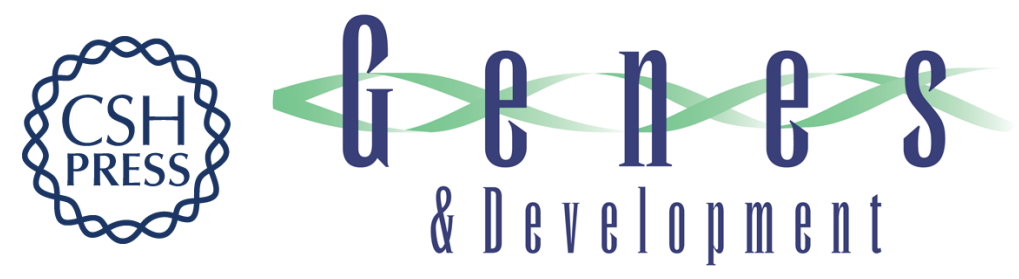

\section{Dynamic association of capping enzymes with transcribing RNA polymerase II}

Stephanie C. Schroeder, Beate Schwer, Stewart Shuman, et al.

Genes Dev. 2000, 14:

Access the most recent version at doi:10.1101/gad.836300

References This article cites 36 articles, 19 of which can be accessed free at: http://genesdev.cshlp.org/content/14/19/2435.full.html\#ref-list-1

License

Email Alerting

Receive free email alerts when new articles cite this article - sign up in the box at the top Service right corner of the article or click here.

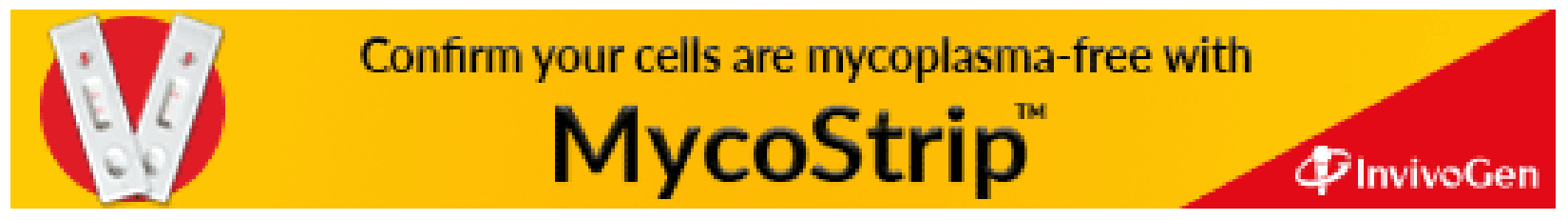

